\title{
Accurate Diagnosis with Chest CT for Bronchial Foreign Body Removal in Young Patient: Report of Three Cases and Review of the Literature
}

\author{
Ye Won Lee, Jae Hyun Cho, Min Bon Koo, and Chang Ki Yeo \\ Department of Otorhinolaryngology, School of Medicine, Keimyung University, Daegu, Korea
}

\section{소아 기관지 이물 제거술을 위한 흉부 전산화단층촬영의 유용성}

이예원 · 조재현 · 구민본 · 여창기

계명대학교 의과대학 이비인후과학교실

\author{
Received June 8, 2014 \\ Revised July 26, 2014 \\ Accepted August 7, 2014 \\ Address for correspondence \\ Chang Ki Yeo, MD, PhD \\ Department of Otorhinolaryngology, \\ School of Medicine, \\ Keimyung University, \\ 56 Dalseong-ro, Jung-gu, \\ Daegu 700-712, Korea \\ Tel $+82-53-250-7715$ \\ Fax $+82-53-256-0325$ \\ E-mail ckyeo@dsmc.or.kr
}

Foreign body aspiration (FBA) is a common accident and remains a serious problem in young children. Undiagnosed and retained FBA could be a life-threatening risk and causes serious complications especially for young children. To prevent complications, prompt diagnosis and removal of foreign body is mandatory. Chest computerized tomography (CT) has recently become a very useful noninvasive diagnostic modality for bronchial FBA. We present here three different patients with bronchial FBA, which had been diagnosed by chest $\mathrm{CT}$ and completely removed under ventilating bronchoscopy without complication. The authors reviewed the literature and discussed the usefulness of chest CT on bronchial FBA in children.

Korean J Otorhinolaryngol-Head Neck Surg 2014;57(12):850-3

Key Words Children · Computerized tomography · Foreign body.

\section{서 론}

기도 이물 흡인은 호흡기 응급상황 중 가장 흔하게 일어나 며 대개 유, 소아에 많이 발생하는 사고로 알려져 있다. 심각 한 경우 즉각적인 응급처치를 시행하지 않으면 생명을 위협 할 수도 있다. ${ }^{1)}$ 신속하고 정확한 진단이 이루어지지 않을 경 우 호흡곤란의 가능성과 함께 폐렴, 무기폐, 기관지 확장증 등 의 심각한 합병증이 발생할 수 있어 세밀한 병력청취와 정확 한 진찰 및 이학적 소견이 매우 중요하다. ${ }^{2)}$

진단을 위한 방사선학적 검사로 과거에는 흥부 단순방사선 촬영을 시행하였지만 최근 흥부 단순방사선촬영(computerized tomography, CT)을 시행함으로써 정확한 위치 및 개수 까지 확인이 가능하다. 기관지 내시경을 이용한 제거술 전 이 러한 확인은 기도 손상 등의 합병증을 줄인다. ${ }^{3,4)}$ 이에 저자들 은 소아 기관지 이물 의심 환자에서 흥부 CT를 통해 정확한 진
단 및 위치를 확인 후 환기형 기관지경술(ventilating bronchoscopy)을 통해 성공적으로 제거한 증례를 문헌고찰과 함께 보 고하고자 한다.

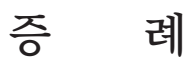

\section{증 례 1}

24개월 된 여아가 내원 1일 전 저녁 7시경에 땅콩을 먹은 후 기침이 지속되어 본원 응급실을 방문하였다. 당일 시행한 흥부 단순방사선촬영에서 우측 흥부에 과도통기 소견(Fig. 1A)을 보였으며 흥부 고해상도 전산화단층촬영(high-resolution $\mathrm{CT}, \mathrm{HRCT}$ )에서 이물질이 우측 주 기관지(right main bronchus)에 $20 \mathrm{~mm}$ 의 길이로 존재하는 것을 확인하였다(Fig. 1B). 전신 마취 하에 강직성 기관지경을 사용하여 이물질(땅콩)을 발견하였고 겸자를 이용하여 제거하였다. 제거 후 시행한 흥부 
단순방사선촬영에서 우측 흥부 과도 통기 소견이 줄어들었 으며(Fig. 1 C) 환자 기침 증상도 줄어들었다. 환자 증상이 호전 되어 수술 후 3 일째 퇴원하였으나 10일 뒤 다시 기침이 심해져 본원에 내원하여 시행한 흉부 HRCT상 우측 주 기관지에 각 각 $4 \mathrm{~mm}, 3 \mathrm{~mm}$ (Fig. 2A), 우측 중간 기관지(right intermediate bronchus)에 $3 \mathrm{~mm}$ (Fig. 2B) 크기의 총 3개의 잔여 이물질이 존재하는 것을 확인하였고 전신 마취 하에 강직성 기관지경 을 이용하여 모두 제거하였다. 수술 후 시행한 흥부 단순방사 선촬영에서 우측 과도 통기가 줄어든 소견을 보였으며 환자
증상이 없어져 수술 2일 후 퇴원하였다.

증 례 2

13 개월 된 여아가 내원 당일 오후 12 시경 점심 식사로 밥과 콩나물을 먹은 뒤 쌕쌕거리는 숨을 쉬며 호흡 곤란 증상이 발생되어 본원 응급실을 방문하였다. 시행한 흥부 단순방사선 촬영에서 우측 흥부에 전반적인 과도 통기 소견(Fig. $3 \mathrm{~A})$ 을 보 였고 훙부 전산화단층촬영에서 우측 주 기관지에 $5 \mathrm{~mm}$ 크기 의 이물질 소견(Fig. 3B)이 보여 전신 마취 하에 강직성 기관지
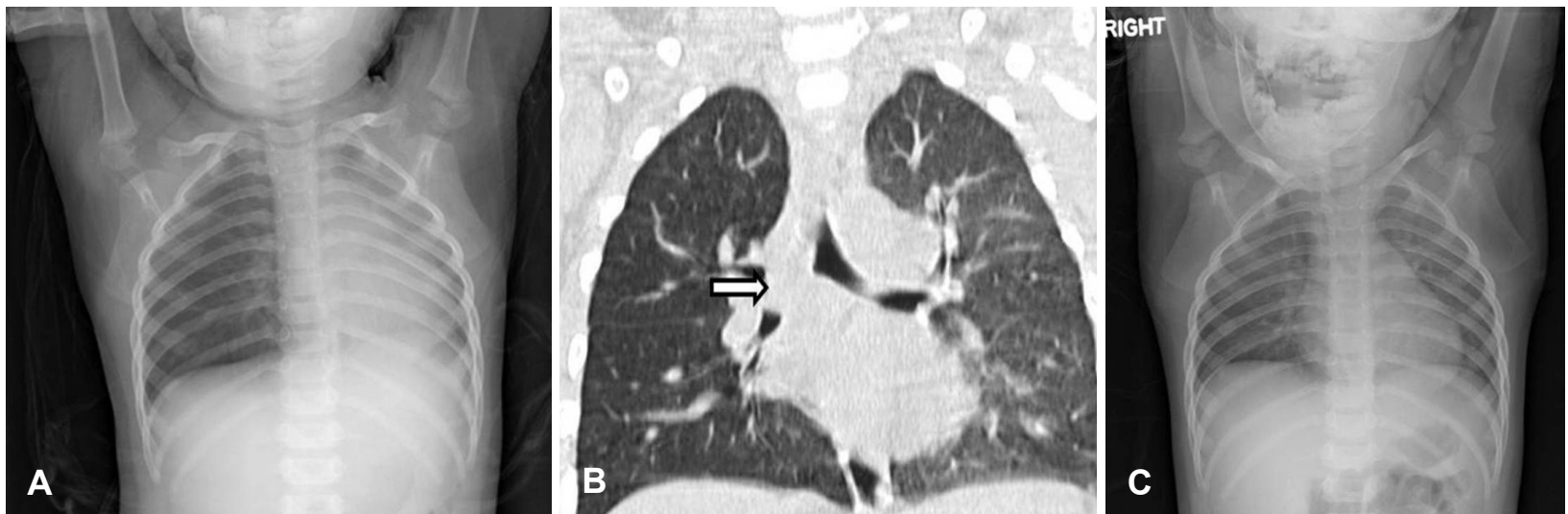

Fig. 1. Chest $X$-ray image shows a hyperinflation of the right lung (A). Chest $C T$ shows a foreign body (arrow) in right main bronchus (B). Postoperative chest X-ray (C)

Fig. 2. Chest CT shows 2 foreign bodies (arrows) in right main bronchus (A). Chest CT shows foreign body (arrow) in right intermediate bronchus (B).
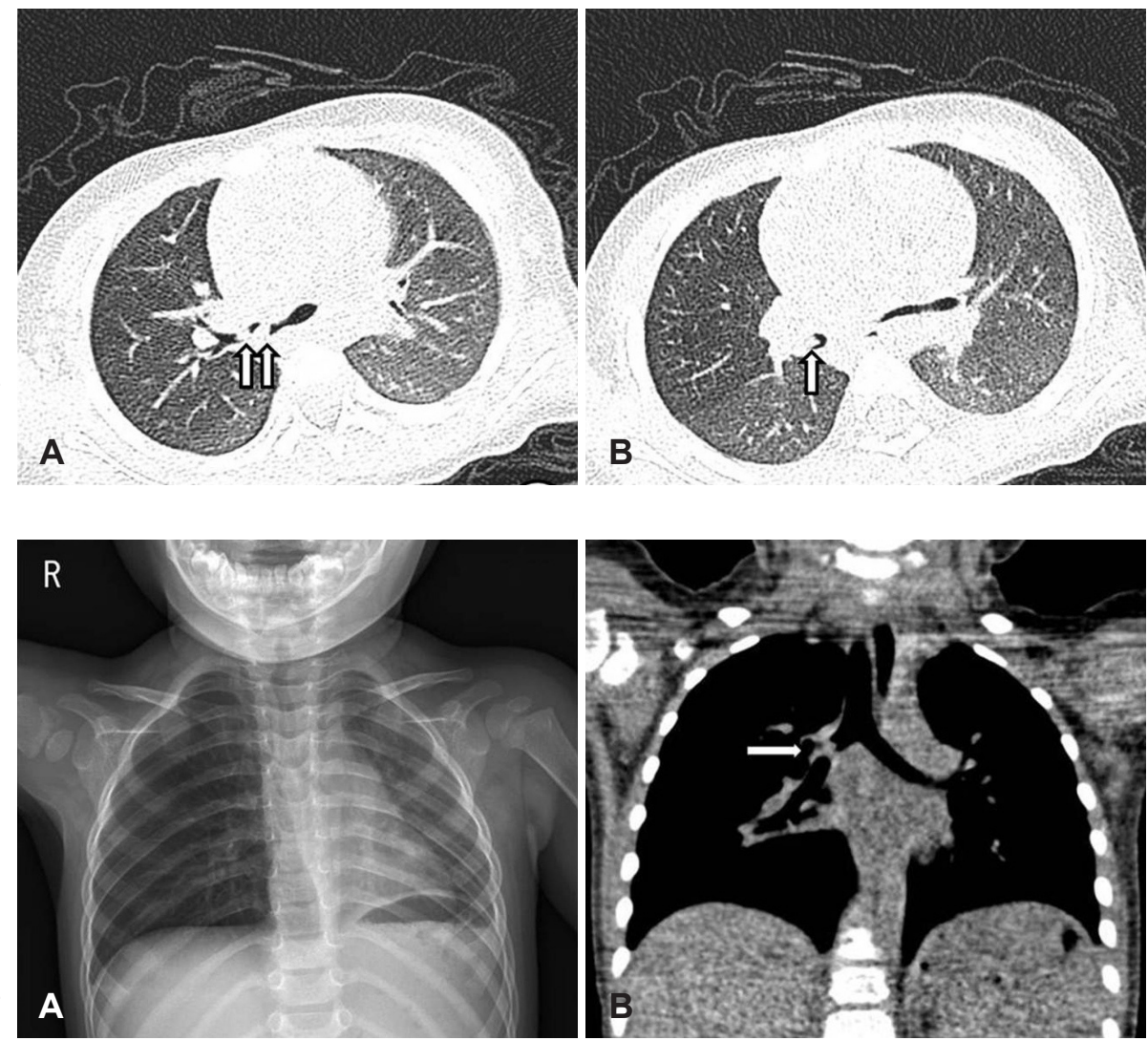

Fig. 3. Chest $X$-ray image shows hyperinflation of the right lung $(A)$. Chest CT shows foreign body (arrow) in right main bronchus (B). 


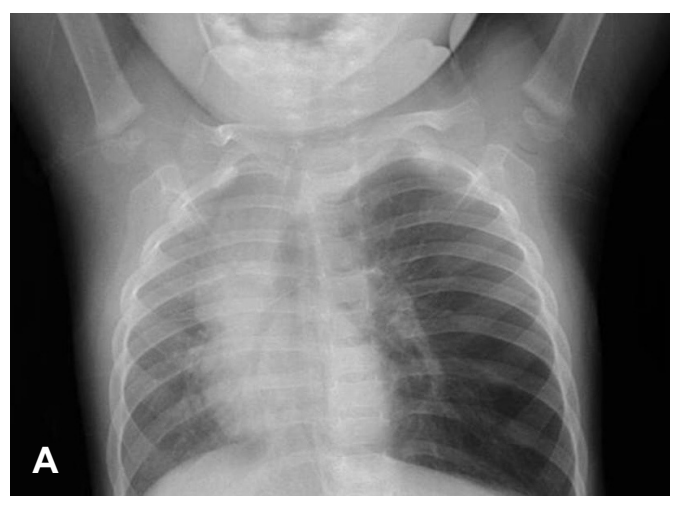

경을 이용하여 콩나물 이물질을 제거하였다.

\section{증 례 3}

16 개월 된 여아가 내원 3일 전 옥수수를 먹다가 캑캑거리는 기침을 하면서 옥수수를 입 밖으로 뱉어 내었으며 그 후 별다 른 증상이 없어 지내다가 1 일 전부터 기침이 심해져 본원 응 급실을 방문하였다. 시행한 흉부 단순방사선촬영에서 좌측 폐기종 소견을 보였으며(Fig. 4A) 흥부 전산화단층촬영에서 좌측 주 기관지에 $5 \mathrm{~mm}$ 크기의 이물질이 발견되어(Fig. 4B) 전 신 마취 하에 강직성 기관지경을 이용하여 이물질(옥수수)을 제거하였다.

\section{고 찰}

기도 이물은 어른보다 소아에서 더욱 흔히 관찰된다. 특히 18 개월에서 3 세 사이의 유, 소아는 이물을 입으로 가져가는 습성을 보이며 대구치의 미발달로 음식 분쇄 능력이 떨어지 고, 음식을 삼킬시 후두상승과 성문의 닫힘이 미성숙한 특정 이 있어 이물이 기도내로 흡인되기가 쉽다. ${ }^{5-7)}$

유, 소아에서 기도 이물은 심각한 합병증을 야기하며 특히 진단이 늦어지는 경우는 더욱 악화될 가능성이 많다. 기도 이 물의 진단은 주로 병력과 이학적 소견을 통해 이루어지나 유, 소아의 경우 스스로 이물 흡인을 표현할 수 없는 경우가 많기 때문에 병력 청취상 애매한 경우가 많으며, 흡인 기왕력 확인 까지 24시간 이상 소요되는 경우도 있다. ${ }^{2,8)}$ 기관지내의 이물 이 장기간 제거되지 않을 경우 호흡기도 점막의 염증과 괴사 를 유발하여 폐렴, 무기폐, 폐기종, 기관지 확장증, 기관지식도 누공 등의 심각한 합병증이 발생할 수 있다. ${ }^{5,9)}$ 해부학적인 차 이로 인해 우측 주 기관지의 직경이 크고 기관과 이루는 각도 가 작아 주로 이물이 우측에 흔하게 위치한다고 하나 항상 그 런 것은 아니므로 위치 확인이 필요하다.,6,7,9)

영상학적 검사는 소아 기관지내 이물을 진단하고 위치를 확인하여 빠른 치료를 돕는다. 이전에 주로 사용된 방법은 흥
부 흡기 및 호기 단순방사선촬영(inspiration-expiration Xray) 및 반복적인 흉부 단순방사선촬영이다. 이물이 방사선 비 투과성이거나 동측의 무기폐, 폐기종 소견이 관찰될 경우 진단에 많은 도움을 줄 수 있으나 이물 흡인 소아의 $30 \%$ 이상 에서 이상 소견이 없을 수 있으므로 방사선촬영 소견만으로 기도 이물의 가능성을 배제할 수 없다.,10) 방사선투시검사(fluoroscopy), 초음파검사, 건조방사선조영술(xenoradiography) 도 시행되어지나 유용성에 한계가 있다. 기도 이물의 가장 정 확한 진단방법은 기관지경술을 통한 직접적인 확인이며, 임 상적 방사선학적 검사에서 기도 이물의 증거가 없는 기도 이 물 흡인이 의심되는 병력을 가진 모든 환자들은 진단적 기관 지경술을 시행해 왔다. ${ }^{11)}$ 그러나 기관지경술 자체가 진단보다 는 치료목적으로 고안되었고 술자의 많은 경험을 필요로 하 며, 침습적이며 성대 손상, 기도 열상, 후두하 부종 등과 같은 합병증 발생의 가능성으로 내포하고 있다. ${ }^{12)}$

최근 기도 및 식도 이물 흡인 환자의 정확한 진단을 위해 흥부 CT가 사용되고 있다. ${ }^{3,411,13)}$ 흥부 CT는 비교적 짧은 촬 영 시간이 소요되어 호흡 조절, 안정 유지 등의 협조가 힘든 유, 소아에서도 유용하게 사용된다. 기관지내 이물 흡인의 경 우 정확히 폐 내부의 미세한 해부학적 구조물을 영상화 할 수 있어 이물질의 위치나 크기를 알 수 있고, 기도부종이나 과팽 창 여부, 주위 폐실질의 이상도 확인할 수 있다. 최근에는 훙 부 고식적 CT(conventional CT)와 더불어 흥부 고해상도 전산 화단층촬영(HRCT), 흥부 다중검출기 전산화단층촬영(multidetector $\mathrm{CT}, \mathrm{MDCT}$ ) 등도 진단에 많이 이용되며 조기 흥부 $\mathrm{CT}$ 가 진단에 크게 유용하며, 높은 민감도와 특이도를 보인 다. ${ }^{11,14)}$ 특히 흥부 MDCT를 사용하면 스캔 시간이 짧고 매우 얇은 절편 두께의 연속적인 단층 영상이 가능하여 이를 통해 다 양한 방향의 임의의 단면으로 영상면을 재구성할 수 있으며 높 은 공간 분해능의 고해상도 영상을 쉽게 얻을 있다. 또한 삼차 원 재구성[3-dimensional(3D) reconstruction]을 통한 기관기 관지분지의 내부 영상을 통해 복잡한 병변을 평가하고 치료계 획을 세우는 데 도움을 준다. ${ }^{11,14,15)}$ 고식적 훙부 CT 소견은 일 
측 혹은 양측성 폐쇄성 폐기종, 무기폐 그리고 실질 침윤(parenchymal infiltration)의 양상이 많이 관찰되며 흥부 $\mathrm{HRCT}$ 는 기관지내의 이물 음영과 공기 걸림 소견(air trapping), 기관 지벽의 비후 소견 등도 확인 할 수 있다. 그러나 흥부 CT는 검 사 시간 동안 고용량의 방사선에 노출되는 단점도 있으며, 이 물질의 종류에 따라 CT로 이물질 존재 여부를 밝힐 수 없는 경우도 있다. ${ }^{15)}$ 그렇지만 임상적으로 이물 흡인이 의심되는 환 아에서 흥부 CT 검사는 다른 검사방법에 비해 높은 진단적 민 감도와 특이도를 보이고 불필요한 기관지경을 피할 수 있는 안 전한 검사 방법이라고 판단된다. 증례 1에서도 HRCT를 통해 서 $20 \mathrm{~mm}$ 의 큰 땅콩 이물질을 제거하였지만 환자의 증상이 다시 발생하여 HRCT를 다시 찍어 남아있는 이물질의 위치 및 크기를 정확히 알 수 있었고 성공적으로 제거하였다.

기도 이물 흡인의 치료는 기관지경을 통한 기도 및 기관지내 이물의 직접적인 확인과 제거가 최선의 방법이다. 유, 소아의 이물 제거 시 주로 강직성 기관지경을 사용하며 전신 마취 하 에서 환기형 기관지경술을 사용하는 것이 안전하다. 굴곡성 기 관지경은 전신 마취가 필요 없고 관찰부위가 넓어 깊숙이 위 치하거나 접근이 힘든 위치의 이물 제거에 용이하며, 이물질 의 존재 여부를 판단할 때 사용되나 시술 도중 지속적 환기 상 태를 유지하기 힘들고 기침반사 유발로 인한 호흡곤란, 이물 위치 변화 등으로 인해 유, 소아에서는 적용이 제한적이다. 기 관지 내시경을 이용한 술식에서 드물게 흡인된 이물질을 모두 다 제거할 수는 없는 경우가 있으며 이런 경우 수술적인 치료 가 필요할 수도 있다. ${ }^{16)}$

본 증례는 모두 본원 소아응급센터를 방문한 환아들로 소 아과 의사가 이물 흡인을 의심하여 흥부 CT 촬영을 우선 시행 하였다. 이를 통해 이물의 정확한 위치, 크기를 알 수 있어 전 신 마취 후 강직성 기관지경을 사용한 이물 제거술을 용이하 게 할 수 있었고 기도 손상 등 합병증의 위험성이 줄었으며 이 미 이물의 개수를 모두 확인하여 잔존 이물 확인을 위한 기관 지경 재검사가 필요 없었다. 그러나 증례 1 의 경우, 이물의 종류 가 땅콩이었기 때문에 제거하는 과정에서 이물이 으스러지며 일부 조각이 깊은 곳으로 밀려 들어가 잔존 이물이 남아 재수 술이 필요하였다. 식물성 이물의 경우 제거 과정에서 더욱 주 의가 필요하며 이물이 부서질 경우 흥부 CT를 확인하였더라도 재확인이 필요하다. 본 병원 마취과에는 제트 인공호흡기(JET ventilator)가 없어 마취과 의사와의 긴밀한 협조를 바탕으로 강직성 기관지경을 이용하여 이물제거술을 시행하였다. 술 중 산소포화도 감소 등의 문제는 없었으며 실제 제거술에 걸린
시간은 증례 1 의 경우 15 분, 증례 2 의 경우 20 분, 증례 3 의 경 우 5 분으로 평균 13 분 가량으로 환기형 기관지경과 큰 차이는 없었다.

\section{REFERENCES}

1) Karakoç F, Karadağ B, Akbenlioğlu C, Ersu R, Yildizeli B, Yüksel M, et al. Foreign body aspiration: what is the outcome? Pediatr Pulmonol 2002;34(1):30-6.

2) Saquib Mallick M, Rauf Khan A, Al-Bassam A. Late presentation of tracheobronchial foreign body aspiration in children. J Trop Pediatr 2005;51(3):145-8.

3) Heo G, Yoo YS, Kim SW. Virtual endoscopy of impacted foreign bodies in tracheal and esophageal model. Korean J OtorhinolaryngolHead Neck Surg 2011;54(5):339-43.

4) Woo KS, Yoo YS, Lee HB, Kim DW, Chang JM, Park JH, et al. Clinical application of 3 dimensional reconstruction of $\mathrm{CT}$ from fish bone foreign body model. Korean J Otorhinolaryngol-Head Neck Surg 2014;57(4):244-50.

5) Midulla F, Guidi R, Barbato A, Capocaccia P, Forenza N, Marseglia $\mathrm{G}$, et al. Foreign body aspiration in children. Pediatr Int 2005;47(6): 663-8.

6) Hsu WC, Sheen TS, Lin CD, Tan CT, Yeh TH, Lee SY. Clinical experiences of removing foreign bodies in the airway and esophagus with a rigid endoscope: a series of 3217 cases from 1970 to 1996. Otolaryngol Head Neck Surg 2000;122(3):450-4.

7) Baharloo F, Veyckemans F, Francis C, Biettlot MP, Rodenstein DO. Tracheobronchial foreign bodies: presentation and management in children and adults. Chest 1999;115(5):1357-62.

8) Bittencourt PF, Camargos PA, Scheinmann P, de Blic J. Foreign body aspiration: clinical, radiological findings and factors associated with its late removal. Int J Pediatr Otorhinolaryngol 2006;70(5):879-84.

9) Tokar B, Ozkan R, Ilhan H. Tracheobronchial foreign bodies in children: importance of accurate history and plain chest radiography in delayed presentation. Clin Radiol 2004;59(7):609-15.

10) Burton EM, Brick WG, Hall JD, Riggs W Jr, Houston CS. Tracheobronchial foreign body aspiration in children. South Med J 1996;89(2):195-8.

11) Koşucu P, Ahmetoğlu A, Koramaz I, Orhan F, Ozdemir O, Dinç H, et al. Low-dose MDCT and virtual bronchoscopy in pediatric patients with foreign body aspiration. AJR Am J Roentgenol 2004;183(6): 1771-7.

12) Zerella JT, Dimler M, McGill LC, Pippus KJ. Foreign body aspiration in children: value of radiography and complications of bronchoscopy. J Pediatr Surg 1998;33(11):1651-4.

13) Adaletli I, Kurugoglu S, Ulus S, Ozer H, Elicevik M, Kantarci F, et al. Utilization of low-dose multidetector CT and virtual bronchoscopy in children with suspected foreign body aspiration. Pediatr Radiol 2007;37(1):33-40.

14) Akira M, Kitatani F, Lee YS, Kita N, Yamamoto S, Higashihara T, et al. Diffuse panbronchiolitis: evaluation with high-resolution CT. Radiology 1988;168(2):433-8.

15) Applegate KE, Dardinger JT, Lieber ML, Herts BR, Davros WJ, Obuchowski NA, et al. Spiral CT scanning technique in the detection of aspiration of LEGO foreign bodies. Pediatr Radiol 2001;31(12): 836-40.

16) Zaupa P, Saxena AK, Barounig A, Höllwarth ME. Management strategies in foreign-body aspiration. Indian J Pediatr 2009;76(2): $157-61$. 